Running Head: Shame memories, paranoia and social anxiety

\title{
The effect of shame and shame memories on paranoid ideation and social anxiety
}

\author{
Marcela Matos $^{1 *}$, MA, Ph.D. Student \\ José Pinto-Gouveia ${ }^{1}$, M.D., Ph.D. \\ Paul Gilbert ${ }^{2,}$ Ph.D., FBPsS.
}

${ }^{1}$ Cognitive-Behavioural Research Centre, University of Coimbra, Portugal
${ }^{2}$ Mental Health Research Unit, University of Derby, UK

* Correspondence concerning this article should be addressed to:

Marcela Matos

CINEICC, Faculdade de Psicologia e Ciências da Educação, Universidade de Coimbra

Rua do Colégio Novo, Apartado 6153

3001-802 Coimbra, Portugal

Telephone: (+351) 239851450

Fax: $(+351) 239851462$

E-mail: marcela.s.matos@gmail.com

This research has been supported by the first author (Marcela Matos) Ph.D. Grant (SFRH/BD/36617/2007), sponsored by FCT (Portuguese Foundation for Science and Technology). 


\begin{abstract}
Background: Social wariness and anxiety can take different forms. Paranoid anxiety focuses on the malevolence of others, while social anxiety focuses on the inadequacies in the self in competing for social position and social acceptance. This study investigates whether shame and shame memories are differently associated with paranoid and social anxieties.
\end{abstract}

Method: Shame, traumatic impact of shame memory, centrality of shame memory, paranoia and social anxiety were assessed using self-report questionnaires in 328 participants recruited from the general population.

Results: Results from path analyses show that external shame is specifically associated with paranoid anxiety. In contrast, internal shame is specifically associated with social anxiety. In addition, shame memories, which function like traumatic memories, or that are a central reference point to the individual's self-identity and life story, are significantly associated with paranoid anxiety, even when current external and internal shame are considered at the same time. Thus, traumatic impact of shame memory and centrality of shame memory predict paranoia (but not social anxiety) even when considering for current feelings of shame.

Conclusion: Our study supports the evolutionary model suggesting there are two different types of 'conspecific' anxiety, with different evolutionary histories, functions and psychological processes. Paranoia, but less so social anxiety, is associated with traumatic impact and the centrality of shame memories. Researchers and clinicians should distinguish between types of shame memory, particularly those where the self might have felt vulnerable and subordinate and perceived others as threatening and hostile, holding malevolent intentions towards the self. 


\section{Key Practitioner Message:}

- Shame and shame memories are distinctively related to paranoia and social anxiety.

- External shame is especially associated with paranoid ideation whereas internal shame is specifically linked to social anxiety.

- The historical route of shame memories, especially those structured as traumatic and central memories to personal identity and life story, may play a significant role in paranoia, perhaps more so than in social anxiety

- Therapy for paranoia or social anxiety should integrate strategies to work with shame.

- Therapeutic interventions with patients experiencing paranoid anxiety should evaluate and address their shame memories, particularly those that function as traumatic and central memories to their self-identity and life narrative.

Keywords: Shame; Shame memory; Autobiographical memory; Paranoia; Social Anxiety; Path analysis 


\section{Introduction}

Evolutionary models have explored social fears and shame, which permeate the social dynamics of human life and represent a major source of suffering.

Fear of conspecifics is common throughout the animal world (Honess \& Marin, 2006). However, for many mammals, especially humans, there are different types of social fear. For example, in the infant-parent relationship fear of separation is an adaptive process that maintains proximity between the carer and cared for (Bowlby, 1969). Humans also gain significant advantages by forming alliances, friendships and a sense of group belonging (Baumeister \& Leary, 1995) and in these contexts social fears can relate to exclusion and rejection (MacDonald, \& Leary, 2005). Gilbert, Broomhead, Irons et al (2008) note that some fears of exclusion or marginalisation can be linked to being passively ignored or 'not chosen' because one lacks certain qualities of attractiveness, but other forms of social exclusion are linked to active rejection involving criticism, harassment and bullying. Dugnan, Trower and Gilbert, (2002) explored two types of social threat related to exclusion and intrusion. In threats of exclusion, fear is focused on displays that fail to impress others or attract much interest. A prominent focus becomes on the deficits of self (in comparison to others). Fear of intrusion, however, is where others get too close; if one does not want to be seen and it is the potential revelation of something negative about the self that is feared (Lewis, 1992).

Common to nearly all animals is, of course, the fear of physical injury related to the hostile intent of others, where the self is the focus of that intent. Typically regarded as paranoid fears, these fears can be linked to in-group social rank anxieties where dominants can threaten and injure subordinates, but subordinates can protect themselves by being avoidant and duly submissive or signalling 'no threat' to dominants (Gilbert, 2001). Although, in many primates, fights between conspecifics are often ritualised, 
injuries and even deaths are not uncommon (Higley et al., 1996). In addition, intense anxieties of other people can also arise from group dynamics where individuals can be injured or killed simply because they are members of a different group; this behaviour has even been noted in chimpanzees (Goodall, 1990). In group conflicts, subordination and submissiveness may not prevent injury and death; for example in gangs and between armies defeated 'enemies' can be killed and injured, even though clearly submitting. In addition, humans are known to plot against and pursue their enemies across time and territories. Paranoid anxieties may be regarded as being related to these conflicts, in that people with paranoia tend to be more distrusting and suspicious of others in general, and have difficulties forming affiliative relationships, even with those who may be of equal status to themselves.

\section{Paranoid anxiety}

Against this background of different social needs and fears of humans there is considerable evidence that conflicts and fear of conflicts have a range of psychological and physiological effects (Honess \& Marin, 2006).

Paranoid anxiety is related to being in the attentional field of others, being negatively evaluated by others (Chadwick \& Trower, 1997) and typically focuses on the harmfulness and hostile intent and/or power of others (Freeman \& Garety, 2004; Gilbert, Boxall, Cheung, \& Irons, 2005). The evolutionary value of paranoia can be linked to the detection of threats to the self from potentially harmful others using the "better safe than sorry" rule (Gilbert, 1998a; Gilbert et al., 2005). Behavioural, psychophysiological and neuropsychological research supports the idea of evolved, specialised systems focused on the detection of social threat being involved in paranoia (Green \& Phillips, 2004). 
Fenigstein and Vanable, (1992) and Ellet, Lopes, and Chadwick, (2003) proposed that paranoia is an 'ordinary' psychological process characterised by a perception of planned intentions of harm by others towards the self rather than implying mental illness. Freeman et al. (2005) also suggest paranoid experiences are common for many people, being almost as common as anxiety and depression. There has been considerable work linking proneness of paranoia to low, unstable or vulnerable self-esteem and attachment difficulties (Pickering, Simpson \& Bentall, 2008).

In an evolutionary framework, it has been argued that representations of the self as inferior, weak, different or subordinate, that is, as a vulnerable self (see Salvatore, Lysaker, Popolo, Procacci, Carcione, \& Dimaggio, 2011 for a discussion on the phenomenological nature of the vulnerable self in paranoia), and of the others as dominant, powerful, devious and threatening, are common features in individuals with paranoid symptoms, particularly those suffering from persecutory delusions (Freeman, 2007; Freeman, Bental, \& Garety, 2008; Freeman, Garety, Kuipers, Fowler, \& Bebbington, 2005; Gilbert et al., 2005; Salvatore et al., 2011). In fact, Gilbert et al. (2005) and Freeman et al. (2005) found paranoia was associated with submissive behaviour, negative social comparisons and perceptions of inferior social rank. Individuals who perceive themselves as inferior to others (particularly feeling left out) may then feel more vulnerable to rejection and attacks, which might contribute to the occurrence of paranoia. These negative perceptions of the self as vulnerable and of others as a potential threat seem to occur in the context of an overactivation of the threat-based social mentality system and an underdevelopment of the safeness system, with an inability to feel safe and tone down distress when facing perceived danger (Gilbert, 2002a; Liotti \& Gilbert, 2010; Salvatore et al., 2011; see Gilbert, 2009, 2010 for a discussion on threat and safeness affect regulation systems). 
In addition, theoretical and empirical accounts in schizophrenia have suggested that some paranoid individuals have deficits in theory of mind, that is, an impaired or altered understanding of others' minds (e.g., of others' intentions, emotions, or thoughts about the self) (Bentall, Rowse, Shryane et al., 2009; Corcoran \& Kaiser, 2008; Corcoran, Mercer, \& Frith, 2005; Frith, 1992, 1944; Lysaker, Salvatore, Grant et al., 2010; Salvatore et al., 2011).

\section{Social Anxiety}

Most psychiatric classifications distinguish between paranoid conditions and those of social anxiety on the basis that paranoid conditions are focused on malevolent intents of others whereas social anxiety focuses on deficits in the self and becomes particularly prominent when people have to act in some way in front of others. For the most part, social anxiety is defined as a fear of creating negative impressions in the minds of others and being negatively judged by them, what will lead to rejection or exclusion (Leary, 1995; Gilbert \& Trower, 2001). For example, a socially anxious person might recognise that others might be kind or pleasant but still not want them for the job, on the team or as a close friend or lover. The fear of being seen as inferior, compared to others, is related to self-presentations and was central to an early model of social anxiety (Schlenker \& Leary 1982; Leary, 1995). It is this focus on the self as (un)attractive, and devalued in the eyes of others, with fear of being negatively judged by them, and high self-focus, that links social anxiety to shame (Clark, \& Wells, 1995; Gilbert, 2001; Gilbert \& McGuire, 1998; Gilbert \& Trower, 1990, 2001; Hackman, Surawy \& Clark, 1998; Keltner \& Harker, 1998; Pinto-Gouveia, 1999). In the cognitive model of social anxiety (Clark \& Wells, 1995), the anxiety is believed to arise from the over monitoring of one's social behaviour and making assumptions about how one is viewed by others (e.g., as boring, odd). The 
focus is on the self as unattractive and unable to impress others, so that they will not choose in one's favour (Gilbert, 2001), and not on the malevolent intent of others.

This means that social anxiety and paranoia can have overlapping features in that both are concerned with how the self 'exists in the mind of others'. Both can be worried about social presentations and both can have concerns about deficits within the self. However, in social anxiety the focus is on our abilities to be attractive to others in competing for social places and avoid negative judgments and rejection, whilst in paranoid anxiety, the focus is on the vulnerabilities of the self in face of dominant and threatening others, with the attribution of motivation in the minds of others being much more malevolent.

\section{Shame}

Therefore, there are many forms of 'social' fear that do not involve the perceived malevolent intent of others, but rather eliciting desirable images and positive feelings about the self in the mind of others so that we are accepted, valued, wanted and chosen. In fact, during the course of mammalian and, in particular, human evolution, there have been major adaptations to the nature of social competition. Interestingly, human competition rarely involves aggression, it is far more focused on competing for social place and position by appearing attractive to others, to be liked, valued and wanted by others (Gilbert, 1997, 1998b, 2009; Gilbert, Price \& Allan, 1995).

Given these needs to compete for social places by creating positive images of our 'selves' in the mind of others (i.e., being an attractive social agent) and thus advance the chances for inclusion, belonging, and being wanted (Leary, 1995; Gilbert \& McGuire, 1998; Keltner \& Harker, 1998; Etcoff, 1999; Gilbert, 1997), shame can act as a warning 
that we 'live in the minds of others' as someone with negative characteristics, or lack of positive ones, and thus are at risk of their rejection, exclusion, being passed by or even persecuted (Gilbert, 2002b, 2007a). Indeed, these are common fears associated with concerns of being seen as inferior to others, as an unattractive social agent (Gilbert, Broomhead, Irons, McEwan, Bellew, Mills, \& Gale, 2007). So, shame emerges from our complex evolved mental abilities to be aware of 'how we exist for others,' and make predictions of what they think and feel about us (Gilbert, 2002b, 2003; Lewis, 1995). Hence shame can be an experience of the self related to how we think we exist in the minds of others (Gilbert \& McGuire, 1998; Keltner \& Harker, 1998), linked to the exposure of negative aspects of the self (e.g., deficits, failures and flaws) to others and to the experience of the others feeling contempt or ridicule for the self ; that is to say, shame is about being seen as an unattractive and undesirable self (Gilbert, 2007a; Lewis, 1993, 2003; Tangney \& Dearing, 2002).

Many researchers of shame also highlight the fact that a sense of self involves a range of evolved high level cognitive, meta-cognitive and symbolic abilities that not only give rise to self-awareness and experiences of the self (Tracy \& Robins, 2004), but also make humans extremely sensitive, focused and responsive to what others think and feel about the self (e.g., theory of mind, Byrne, 1995; Gilbert, 2002b, 2007a). Shame therefore belongs to a family of emotions that are called self-conscious emotions (Tangney \& Fischer, 1995), which play a central role in motivating and regulating people's thoughts (e.g. self and other representations), feelings, and behaviours (Tracy \& Robins, 2004, 2007).

Shame, however, can also be distinguished in terms of its attention focus, thoughts and behaviour (Gilbert, 1998b, 2003). External shame is a term used to focus on the shame we experience when we believe we are held negatively in the mind of others. 
In external shame our attention is focused on the mind of the other, our behaviour might be orientated towards trying to influence our image in the minds of others by appeasing or displaying qualities we hope will find favour. Internal shame, on the other hand, is focused on the self; we are both judge and judged. Our attention is focused inwardly, on our mistakes and self deficits and we are commonly self-critical. Even in the context of other people feeling positively about us, we can still have negative views about ourselves and feel inferior and inadequate in comparison to others (Gilbert 1998b, 2002b, 2007a).

\section{Autobiographical memory, paranoia and social anxiety}

Sensitivity to both paranoid and social anxiety may arise from aversive experiences with other people in childhood. However, it is unknown whether shame experiences that function as traumatic and central autobiographical memories may orientate a person to a malevolent form of anxiety focused on others' intentions towards the self (paranoia) or to a form of social fear focused on the inadequacies of self (social anxiety).

Autobiographical memory (AM) is of crucial importance to one sense of self and view of others (Conway \& Pleydell-Pearce, 2000; Conway, Singer, \& Tagini, 2004). AM can be defined as the "memory for the events of one's life" that "constitutes a major crossroads in human cognition where considerations relating to the self, emotion, goals, and personal meanings all intersect" (Conway \& Rubin, 1993, p.103).

A recent model of AM, the Self Memory System (Conway, 2005; Conway \& Pleydell-Pearce, 2000; Conway, Singer, \& Tagini, 2004), highlights the interconnectedness of the self, defined as a complex set of goals and associated selfimages (i.e., the working self), and memory, viewed as the data base of the self. When the working self and the autobiographical memory knowledge base interconnect in acts of 
remembering, autobiographical memories can be formed. An integrative part of the working self is the conceptual self (Conway, Meares, \&Standart, 2004), which consists of socially constructed schema and categories that define the self, other people, and typical interactions with others and the world [e.g., internal working models of self and others (Bowlby, 1969/1982, 1973, 1980), self-with-other units (Ogilvie \& Rose, 1995), relational schema (Baldwin, 1992), personal scripts (Singer \& Salovey, 1993; Thorne, 2000, 1995; Tomkins, 1979)].

Three broad theoretical functions of AM have been proposed in the literature and are especially relevant in the discussion of shame memories: people use personal memories to serve self, social and directive functions (Bluck, 2003; Bluck, Alea, Habermas, \& Rubin, 2005). The self function pertains to AM's role in the content of identity, in the maintenance of a coherent sense of self over time (Addis \& Tippet, 2008; Bluck \& Levine, 1998; Conway, 2005; Habermas \& Bluck, 2000; McAdams, 1996; McLean \& Thorne, 2003; Wilson, \& Ross, 2003), or in the construction of working models of self and others (Conway, 2003). The social function of AM includes using memories to develop, maintain and nurture social bonds, to initiate relationships, and to better understand and empathise with others (Alea \& Bluck, 2003; Cohen, 1998; Pillemer, 1998; Robinson \& Swanson, 1990). The directive function of AM involves using our own past experience to solve current problems and guide future behaviours (Baddeley, 1986; Cohen, 1998), or to construct models of others' inner world that allow us to predict their future behaviour and thereby influence our cognitions, emotions and behaviours towards them (Robinson \& Swanson, 1990). Pillemer $(1998,2003)$ further discussed the guiding power of AM, suggesting that individual personal memory episodes can play strong directive roles in people's lives (e.g., functioning as anchors for self conceptions and values, or as turning points in life story). 
Following this view, is the Centrality of Event Theory, in which Berntsen and Rubin $(2006,2007)$ propose that a memory of a trauma or a negative emotional event can become a central component of identity, a turning point in the life story or reference point for everyday inferences and for generating expectations central to one's life story and this may be related to increased levels psychopathology.

Therefore, if intrapersonally AM is a critical component in mental representations of the self, and interpersonally, it provides a basis for creating mental models of others and establishing and maintaining social relationships (Kihlstrom, 2009), one would expect that the way shame experiences function in the AM might influence the vulnerability to developing social or paranoid anxiety, since these two forms of social wariness involve different inner working models of self and others.

\section{Shame memories, paranoia and social anxiety}

Shame experiences can occur very early in life and comprise a primary threat to the (social) self (Gilbert, 1998, 2003), so shame memories can texture the whole sense of self (Andrews, 2002; Andrews \& Hunter, 1997). Shame memories are threat memories. For example Kaufman (1989) suggested that shame memories operate like mini-scenes in the mind, and emotional hot-spots. Shame memories can be associated with a sense of vividness and high emotional affect; typical here are memories of: painful bullying, criticism from a parent, failing an important exam where one thought one would pass, sexual impotency and so on. Such threat memories have powerful emotional effects on self-schema with potential to create intrusions (Baumeister et al., 2001; Dickerson \& Kemeny, 2004).

In a recent study, Matos and Pinto-Gouveia (2010) found that early shame experiences reveal traumatic memory characteristics (e.g. intrusion, avoidance, hyper- 
arousal) that not only have an impact on feelings of shame in adulthood but also moderate the impact of shame on depression. Additionally, Pinto-Gouveia and Matos (2011) suggest that early shame experiences are recorded in autobiographical memory as powerful and distressing emotional memories that can become central to a person's identity and life story. Furthermore, they found that the centrality of shame memories shows a unique and independent contribution to depression, anxiety and stress prediction, even after controlling for shame measures, and that the centrality of shame memories is highly and positively associated with traumatic stress reactions.

The way shame experiences operate in AM, and function as traumatic and central memories to the identity and life story for those experiencing social anxiety and those experiencing a more malevolent or paranoid form of anxiety, has not yet been explored. For example, are people prone to the paranoid forms of social anxiety more likely to have shame memories with traumatic characteristics and that have become central AMs to their identity and life story (e.g. coming from more malevolent backgrounds high in abuse)? Do people with less malevolent forms of social anxiety have shame memories that function as less traumatic and central in their AM (e.g. coming from backgrounds of needing to impress others to feel wanted or loved)?

Aims

This study set out to explore the relationship between shame and shame memories, specifically the traumatic nature and centrality of early shame experiences, with social anxiety and paranoia.

This study intends to test if external and internal shame have a different impact on paranoid and social anxiety. Given that external shame is related to the negative image of the self in the minds of others and internal shame is associated with the undesirability and 
inadequacy of the self in its own eyes, we hypothesise that external shame would have a higher effect on paranoia (more linked to malevolent intents of others towards the self) whereas internal shame would have a higher impact on social anxiety (more focused on the deficits of the self that may lead to rejection by others).

In addition, we set out to investigate whether the degree to which shame memories function in AM as traumatic and central to one's identity and life story has a different impact on paranoia and social anxiety, when current shame feelings are considered simultaneously (since shame plays an important role in paranoia and social anxiety). We hypothesised that the traumatic and central shame memories, would have a higher impact on paranoid anxiety compared to social anxiety. This is because we suggest that the more traumatic and central early shame experiences are recorded in AM, the more likely they are to generate a malevolent sense of threat to the self, leading to perceptions of others as hostile and harmful, and the self as rejectable, inferior, flawed or powerless. Finally, this study, also intends to extend previous findings (Matos \& PintoGouveia, 2009; Pinto-Gouveia \& Matos, 2010) on the association between shame, shame memories and psychopathology using a different community sample.

\section{Method}

\section{Participants}

Participants in this study were 328 subjects recruited from the general community population in the district of Coimbra, Portugal. Participants mean age was 37.3 years (SD $=11.7$; age ranging from 20 to 70 years $), 67.1 \%$ were females $(n=220)$ and $32.9 \%$ males $(n=108)$. Fifty per cent of the subjects are married $(n=163)$ and $37 \%$ are single $(n=$ 122). Forty seven per cent have middle class professions (e.g., academics, teachers, social workers, engineers, managers, nurses, middle-level administrators) $(n=153)$. The mean 
number of years in education is $13.4(S D=4.5)$. Gender differences were tested for and no significant differences were found between men and women in the study variables.

\section{Procedure}

Participants were given a series of self-report questionnaires designed to measure external shame, internal shame, traumatic and autobiographical memory characteristics, social anxiety and paranoia. The questionnaires were administered by the author, MM, with assistance of undergraduate students. A convenience sample was collected from the general population, recruited within the staff of institutions, namely schools and private corporations. These institution's boards were contacted, the research aims were explained and authorisation was obtained so that their employees could participate in the study. Afterwards, staff were contacted by email, which explained the nature of study and invited them to participate. Participants then met with a researcher, who explained the study in detail and sought informed consent, and then completed the self-report questionnaires. In line with ethical requirements, it was emphasised that participants cooperation was voluntary and that their answers were confidential and only used for the purpose of the study.

\section{Measures $^{a}$}

All instruments used in this study were translated into Portuguese by a bilingual translator and the comparability of content was verified through stringent back-translation procedures.

\footnotetext{
${ }^{a}$ The individual questionnaires were administered in the following order across participants: Others As Shamers, Experiences of Shame Scale, Impact of Event Scale-Revised, Centrality of Event Scale, Social Interaction and Performance Anxiety and Avoidance Scale, General Paranoia Scale.
} 
Shame

Other As Shamer (OAS; (Allan, Gilbert, \& Goss, 1994; Goss, Gilbert, \& Allan, 1994; Portuguese version by Matos, Pinto-Gouveia , \& Duarte, 2011a), is 18 item selfreport scale that measures external shame (i.e., global judgements of how people think others view them). Respondents rate on a 5-point Likert scale $(0-4)$ the frequency of their feelings and experiences, for example, "I feel other people see me as not quite good enough" and "I think that other people look down on me". Scores can range from 0 to 72 with higher scores on this scale indicative of higher external shame. A Cronbach alpha of .92 was reported in the original study of this scale Goss et al. (1994). In the present study, the Cronbach alpha was .91.

Experience of Shame Scale (ESS; Andrews, Qian, \& Valentine, 2002; Portuguese version by Matos, Pinto-Gouveia, \& Duarte, 2011b) is a27 item scale that assesses three areas of (internal) shame: character (e.g., "Have you felt ashamed of the sort of person you are?"), behaviour (e.g., "Have you tried to cover up or conceal things you felt ashamed of having done?") and body (e.g., "Have you felt ashamed of your body or any part of it?"). Each item indicates the frequency of experiencing, thinking and avoiding any of the three areas of shame in the past year and is rated on a 4-point Likert scale (1 4). Scores can range from 27 to 108 . Only the total of the ESS was used in this research as a measure of internal shame. Andrews et al. (2002) found this scale to have a high internal consistency (Cronbach $\alpha=.92$ ) and in the present study, ESS total showed a Cronbach alpha of .94 .

\section{Shame memories}




\section{Traumatic impact of shame memory}

Impact of Event Scale - Revised (IES-R; Weiss \& Marmar, 1997; Portuguese version by by Matos, Pinto-Gouveia, \& Martins, 2011) is a 22-item self-report instrument designed to measure traumatic stress reactions and current subjective distress for any specific life event and, distinctively in our study, a shame experience from childhood or adolescence. It is rated on a 5-point Likert scale $(0-4)$. The IES-R is composed of three subscales that measure the three main characteristics of traumatic memories: avoidance (e.g., "I stayed away from reminders of it"), intrusion (e.g., "Any reminder brought back feelings about it") and hyperarousal (e.g., "I was jumpy and easily startled") that parallel the DSM-IV criteria for PTSD. In this study only the total of the IES-R will be used and it is computed by the sum of the total of the three subscales. Scores can range from 0 to 12. In the original study, Cronbach alphas of the subscales ranged from .87 to .92 for intrusion, .84 to .86 for avoidance and .79 to .90 for hyperarousal (Weiss \& Marmar, 1997). In this study, the total of IES-R revealed high internal consistency (IES-R Cronbach $\alpha=.97)$.

\section{Centrality of shame memory}

Centrality of Event Scale (CES; Berntsen \& Rubin, 2006; Portuguese version by , Matos, Pinto-Gouveia, \& Gomes, 2010) assesses the extent to which a memory for a stressful event forms a reference point for personal identity and to attribution of meaning to other experiences in a person's life. It consists of 20 items, rated on 5-point Likert scales (1-5), that measure three interdependent characteristics of highly negative emotional memories: reference points for everyday inferences (e.g., "This event has coloured the way I think and feel about other experiences."), turning points in life stories (e.g., "I feel that this event has become a central part of my life story.") and components 
of personal identity (e.g., "I feel that this event has become part of my identity."). Scores can range from 20 to 100 . In its original study, CES reported a high internal consistency (Cronbach $\alpha=.94)$. In this study, CES also showed an excellent internal consistency (Cronbach $\alpha=.96)$.

\section{Priming for a shame memory}

In this study, instructions for the IES-R and the CES were modified to prime participants with a shame memory and complete the scale with that memory as their focus. Participants were instructed to answer the questionnaire based on a significant and stressful shame experience they recalled from their childhood or adolescence.

Participants were given a brief introduction about the concept of shame and then given the filling instructions:

"The experience of shame is common among all human beings and everyone, throughout life, has shame experiences. We know now that these are important experiences that might be related to several problems in people's lives. In this questionnaires we are interested in getting to know your shame experiences, that is, a situation where you felt shame. Shame is a negative self-conscious emotion associated with feelings of inferiority and personal devaluation. Shame may involve different feelings and thoughts:

- External shame is what we feel if we experience or think someone/others are being critical, hostile, looking down on us or seeing us as inferior, inadequate, different, bad or weak; is what we feel when others criticise, reject, exclude or abuse us. Our feelings rise from how we feel others feel about us.

- Internal shame is what we feel when we feel or judge ourselves negatively, as inferior, inadequate, different, bad or weak. Our feelings rise from how we feel and think about ourselves.

In a certain situation we might feel external shame, internal shame or both.

Shame feelings may blend with other feelings like anxiety, fear, anger, disgust or contempt. Furthermore, a great urge to hide, disappear or run away from the situation is part of the experience of shame.

Now, please try to recall a (significant) situation or experience in which you think you felt shame, during your childhood and/or adolescence. 
(For the IES-R) Using the following scale, please indicate the degree of distress that each difficulty has caused you throughout your life. That is, concerning the shame experience you recalled, how much were you distressed by these difficulties?

(For the CES) Please think back upon that significant shame event in your life and answer the following questions in an honest and sincere way, by circling a number from 1 to 5."

We consider that this adjustment in the instructions does not seem to affect the validation of these scales, since the items' content is well suited for both instructions.

\section{Social Anxiety}

Social Interaction and Performance Anxiety and Avoidance Scale (SIPAAS; Pinto-Gouveia, Cunha, \& Salvador, 2003) is a self-report scale that measures the degree of anxiety and avoidance in social situations. This scale comprises 44 items that represent performance and social interaction situations (e.g., "Go to a party", "Ask someone out", "Do an oral exam" "Ask a stranger for information"). For each situation, subjects are asked to rate in 4-point Likert scale $(1-4)$ the degree of discomfort/anxiety felt and the extent to which they avoid that situation. This instrument is composed of two subscales: Discomfort/Anxiety and Avoidance, however only the total will be used in this study. The total SIPAAS score can range from 88 to 352. In its original study, the scale showed good internal consistency (Cronbach $\alpha=.95$ for Discomfort/Anxiety subscale and .94 for Avoidance subscale). Similarly, in the present study Cronbach' alpha values were of .97 for the scale total, .96 for Discomfort/Anxiety and .95 for Avoidance.

\section{Paranoia}

General Paranoia Scale (GPS; Fenigstein \& Vanable, 1992; Portuguese version by Lopes \& Pinto-Gouveia, 2005) is a 20 item self-report paranoia scale designed to measure paranoia in college students. It assesses the following characteristics: the belief 
that another person, or a powerful external influence, is commanding the individual's thoughts and behaviours (e.g., "Someone has been trying to influence my mind"); the belief of a conspiracy against oneself, i.e. others are working together to conspire against the individual (e.g., "My parents and family find more fault in me than they should"); the belief of being spied on and talked negatively about oneself behind one's back (e.g., "I sometimes feel as if I am being followed"); a general suspicion regarding others and a lack of trust on people (e.g., "It is safer to trust no one.") and finally the presence of feelings of resentment (e.g., "I am sure I get a raw deal from life"). Each item is rated on a 5-point Likert scale $(1-5)$. Scores can range from 20 to 100, with higher scores indicating greater paranoid ideation. Fenigstein and Vanable (1992) found this scale to have good internal consistency across their four North-American samples (Cronbach $\alpha=$ .84). The GPS showed a Cronbach alpha of .91 in our sample.

\section{Statistical analysis}

Analysis was conducted using PASW, version 18 (IBM, SPSS) for PCs.

In order to explore the relationship between shame, traumatic impact of shame memory, centrality of shame memory, paranoia and social anxiety (continuous variables) we conducted Pearson product-moment correlations (Cohen, Cohen, West, \& Aiken, 2003).

With the purpose of better understanding the impact of the traumatic impact of shame memories, centrality of shame memories, external shame and internal shame (exogenous/independent variables) on paranoia and social anxiety (endogenous/dependent variables ), we conducted two path analyses. This technique is a special case of Structural Equation Modelling and considers the hypothetic casual relations between variables that have already been defined. It is assumed that there is no 
measure error, and that there is multivariate normality (which we tested) (Tabachnick \& Fidell, 2007). A Maximum Likehood estimator was used to calculate the equation, in AMOS 18. SEM procedure estimates the optimal effect of one set of variables on another set of variables in the same equation, controlling for error (Byrne, 2010; Kline, 2005). Path analysis uses latent variables already calculated instead of the full factorial model that considers observed variables in the model (Kline, 2005). Two separate path analyses were performed because both the traumatic impact of shame memory and centrality of shame memory refer to the same shame memory, and so they share high covariance between them.

\section{Results}

Descriptives

The means and standard deviations for this study are presented on Table 1.The descriptive statistics for the variables studied were similar to previous studies (e.g., Andrews et al., 2002; Berntsen \& Rubin, 2006, 2007; Goss, Gilbert, \& Allan, 1994; Matos \& Pinto-Gouveia, 2010; Pinto-Gouveia \& Matos, 2011; Weiss \& Marmar, 1997).

Table 1 around here

\section{Correlations}

The Pearson product-moment correlations are presented in Table 2. Pertaining to the association between shame, paranoia and social anxiety, we found that external shame had a positive strong correlation with paranoia, and positive moderate correlation with social anxiety and avoidance. Internal shame was moderately correlated with general paranoid ideation and strongly associated with social anxiety and avoidance. 
Concerning the relationship between traumatic and centrality characteristics of shame memories and paranoid and social anxiety, results revealed that traumatic impact of shame memory was particularly associated with paranoid anxiety, showing positive and moderate correlations with paranoid ideation. It was also related to social anxiety but the correlations were weaker. Similarly, centrality of shame memory was primarily associated with paranoia, showing positive and moderate correlations with paranoid ideation, and weaker correlations with social anxiety.

So, individuals whose shame memories from childhood and adolescence had traumatic memory features (e.g. of intrusion, avoidance, hyper-arousal) and were regarded as central components of personal identity and life story and as reference points to give meaning to past, current or future experiences, tended to show increased paranoid ideation. Social anxiety was also associated with these traumatic and central shame memories but the correlations were weaker than with paranoia.

Table 2 around here

To better understand the impact of shame traumatic and central memories on paranoia and social anxiety, when considering at the same time the effect of current feelings of shame, we conducted two structural equation models.

\section{Path analysis}

First, we tested a model considering three exogenous variables: traumatic impact of shame memory, external shame, internal shame, and two endogenous dependent variables: paranoia and social anxiety (Figure 1). 
Figure 1 around here

In the evaluation of model $\mathrm{A}$, we found a very good model fit with a nonsignificant chi-square test (Table 3). Six goodness-of-fit indices were chosen for the evaluation of model fit: GFI, AGFI, CFI, TLI, RMSEA, SRMR, because they are well known and recommended in the literature (Kline, 2005). The analysis of these indices revealed an excellent model fit.

All the paths considered in the model were statistically significant, with the exception of the relation between traumatic impact of shame memory (IES-R) and social anxiety (SIPAAS). Regarding the impact on paranoia (GPS), we can see that external shame (OAS) was the strongest predictor, followed by traumatic impact of shame memory (IES-R). Internal shame (ESS) showed the lowest regression weight (Table 3).

In relation to social anxiety (SIPAAS), only current external and internal shame feelings had a significant impact. Internal shame (ESS) was the predictor that had the higher impact and external shame (OAS) showed a lower regression weight.

Table 3 around here

In model $\mathrm{B}$, three exogenous variables were considered: centrality of shame memory, external shame, internal shame, and two endogenous variables: paranoia and social anxiety (Figure 2).

Figure 2 around here

In the evaluation of the adjustment of model $\mathrm{B}$, a low but significant chi-square test was found. This result, along with the goodness-of-fit criteria, allowed us to conclude 
that the model had an acceptable fit. Specifically, regarding baseline comparisons (CFI, TLI), results were higher than the recommended cut off values (.95). Concerning indices for the parsimony of the model, despite RMSEA had a higher value than the recommended cut-off point (.08), SRMR showed a value much lower than the cut-off point (.10). The absolute fit index, GFI, was very close to the perfect fit (cut off $>.90$ ) (Kline, 2005). Overall, given these global adjustment results and the local adjustment considering the regression paths, this model may constitute a good explanation for these relationships.

All the paths in the model were statistically significant, with the exception of the relation between centrality of shame memory (CES) and social anxiety (SIPAAS). External shame (OAS) was the strongest predictor of paranoia (GPS), followed by centrality of shame memory (CES). Internal shame (ESS) showed the lowest regression weight for the prediction of paranoia (GPS) (Table 3).

As seen in model A, only current external and internal shame feelings had a significant impact on social anxiety (SIPAAS). Internal shame (ESS) was the most significant predictor followed by external shame (OAS), which showed a lower regression weight.

Therefore, the key finding is that external shame (i.e. feeling one lives in the minds of others as inferior, unworthy, unattractive social agent) is mainly associated with higher paranoia scores. In contrast, higher internal shame (i.e. feeling and seeing oneself as inadequate, inferior and unattractive) is mostly linked to social anxiety.

Furthermore, the two path analyses consistently show that individuals whose shame memories function as traumatic memories, that elicit intrusions, avoidance and symptoms of hyper-arousal, or as central reference points to their self-identity and life story, present higher general paranoid ideation, even when current feelings of external 
and internal shame are considered at the same time. Thus, traumatic impact of shame memory and centrality of shame memory predict paranoia, but not social anxiety, even when current feelings of shame are simultaneously tested.

\section{Discussion}

This study investigated the role of shame, traumatic impact and centrality of shame memories in relation to paranoia and social anxiety. These two forms of anxieties have different evolutionary histories and may be regulated by different psychological processes (Gilbert, 2001).

We distinguished between internal shame and external shame and found that external shame was more associated with paranoid anxiety, whilst internal shame was more correlated with social anxiety, although there were obvious overlaps. According to our hypothesis, similar results were found in both path analyses where external shame had a higher impact on paranoia and internal shame showed a higher impact on social anxiety. These findings are in line with the view that paranoid anxiety is focused on the malevolent intentions of others towards the self (Fenigstein \& Vanable, 1992; Freeman \& Garety, 2004; Freeman et al., 2005; Gilbert et al., 2005) and that it is closely related to interpersonal threats, particularly, being negatively evaluated by others (Chadwick \& Trower, 1997). In contrast, social anxiety is more closely linked to a sense of an inadequate and undesirable self, unable to win in the competitive arenas for friends, lovers, and status, with a greater focus on the sense of self and internal shame (Clark, \& Wells, 1995; Gilbert \& McGuire, 1998; Gilbert \& Trower, 1990, 2001; Keltner \& Harker, 1998; Gilbert, 2001; Ogilive, 1987).

In regard to shame memories, we found that the more traumatic and central to identity and life story the shame memory is, the higher its association with paranoid 
anxiety. Also, results from two path analyses showed that, when current shame feelings are considered simultaneously, traumatic impact of shame memory and the centrality of shame memory independently predict paranoid anxiety, but not social anxiety. These results suggest that the way shame memories are organised and function in AM might be an important factor to differentiate paranoid from social anxiety. Thus, this suggests that researchers should distinguish between types of shame memory, particularly those where the self might have been the target of hostile actions by others, for example, shame episodes where one was treated with contempt, humiliated or attacked by others, and felt they hold malevolent intentions towards the self.

This implies that in paranoid anxiety, shame memories appear to operate in AM as trauma memories, capable of eliciting intrusions, avoidance and symptoms of hyperarousal. In light of recent perspectives in traumatic memory (Ehlers \& Clark, 2000) and paranoia (Freeman, 2007; Freeman et al., 2008; Gilbert et al., 2005; Salvatore et al., 2011), early shame experiences that function as traumatic memories might contribute to the maintenance of a permanent sense of threat to the (social) self, who is left to feel vulnerable, inferior, subordinate, powerless or undesired, and a view of others as dominant, hostile and threatening, who may harm, reject, exclude or persecute the self. This might thus result in (or reinforce) a hyperactivation of the threat and self-protection system in face of (perceived) menaces to the self as a social agent as well as compromise the access to feelings of safeness and security, elevating vulnerability to experience paranoid symptoms.

In addition, shame memories (where the self might have been threatened, rejected, harmed or abused by hostile, critical or powerful others) seem to function as anchoring events for one's sense of self-identity and as turning points in one's life narrative. So, these shame experiences can form highly available reference points for the organisation 
of other memories and remain too central to the understanding of one's past, present and future, shaping not only our negative perceptions of the way we exist in the minds of others but also our view of others as hostile and threatening, with malevolent intentions towards the self. This would explain the greater association of shame memories with paranoia, rather than social anxiety, because while paranoid anxiety is more focused on the negative thoughts and malevolence of others, social anxiety is more focused on the inadequacies of the self.

The present findings extend the work of Matos and Pinto-Gouveia (2010) and Pinto-Gouveia and Matos (2011) on the traumatic and autobiographical nature of shame memories and their relationship to psychopathology. Our results might be viewed in light of current conceptualisations of AM (Conway, 2005; Conway \& Pleydell-Pearce, 2000; McLean, 2005; Thorne, 2000; Singer \& Salovey, 1993), suggesting that shame memories that are perceived as traumatic and central AMs might function as self-defining memories in the Self Memory System, especially in those individuals who suffer from paranoid anxiety. In these individuals, shame AMs might have served self, social and directive functions (Bluck et al, 2005). These shame memories might have led to structuring negative mental models of self (e.g., as being negatively evaluated by others, powerless, inferior) and others (e.g., as threatening and hostile that may harm, reject, exclude or persecute the self), which influence cognitions and emotions regarding others (e.g., paranoid thoughts and anxiety) and the way one develops and maintains social relationships (Addis \& Tippet, 2008; Conway, 2003, 2005; McLean, 2005; Pillemer, 2003; Robinson \& Swanson, 1990; Wilson \& Ross, 2003).

Furthermore, these findings are consistent with the concept of centrality of a (trauma) memory that, being highly integrated in autobiographical memory, can form a cognitive reference point for the organisation of autobiographical knowledge and for 
perception of the self, others and the world, influencing subsequent attentional, emotional and cognitive processing (Bernsten \& Rubin, 2006, 2007). In light of this model, our results might suggest that when shame is linked to a central AM it may bias attention and social processing to threat and malevolence. Given that shame memory can be traumalike, with intrusions, avoidance and hyper-arousal symptoms, these processes may create biases towards interpersonal threat, thus increasing vulnerability to paranoid anxiety. This is in line with cognitive, psychophysiological, neuropsychological, and neuroimaging evidence on social threat detection processes involved in paranoia (for a review, see Green \& Phillips, 2004). However, further empirical support for these linkages between shame memories and threat processing is required.

Our results may also sit with empirical evidence that individuals with paranoid symptoms present impairment in understanding others' minds (Corcoran et al., 2005; Lysaker, 2010; Salvatore et al., 2011). An hypothesis is that in some individuals, shame memories that involved a sense of self as vulnerable and of others as threatening and hostile, might have lead to deficits in theory of mind abilities which, in turn, elevated their proneness to misunderstand others' intentions, emotions and thoughts. This speculation constitutes a possible interesting avenue for future research.

The current study adds to previous research suggesting paranoia and social anxiety problems might be related to neglectful or abusive backgrounds (Freeman et al., 2002; Gilbert, 2002a; Gilbert, Allan \& Goss, 1996; Gilbert et al., 2005; MacBeth, Schwannauer, \& Gumley, 2008; Mills et al, 2007; Gracie et al., 2007; Trower \& Chadwick, 1996). In fact, our study suggests that traumatic shame experiences from childhood and adolescence, where one might have been rejected, excluded, criticised or abused by significant others, may be particularly important in paranoid anxiety. These adverse experiences can lead to the formation of negative views of the self (e.g., as 
undesirable, bad or defective) and of others (e.g., as hostile, threatening, unpredictable, bad), and to the development of a current sense of threat to the self posed by others, from whom one should defend against. Nevertheless, it is also conceivable that people who currently experience higher levels of shame and suffer from paranoid anxiety may be more inclined to judge a shame related childhood memory as traumatic and central to their life story and identity, or even distort memories in order to confirm that others are hostile and threatening. Several studies give support for this view suggesting that the emotional content of an experience can influence the way the event is remembered, and that the appraisals, emotions and emotional goals at the time of autobiographical retrieval can influence the information recalled (for a review, see Levine \& Pizarro, 2004 and Holland \& Kesinger, 2010).

However, although current emotional states may influence how we construct our past, the fact that the traumatic impact and the centrality of shame memories predict paranoid ideation even when current feelings of shame are considered simultaneously, supports our interpretation. Furthermore, the choice of the exogenous and endogenous variables entered in the path analyses was founded on theoretical models (Berntsen \& Rubin, 2006, 2007; Ehlers \& Clark, 2000; Gilbert, 1998, 2002) and on previous findings (Matos, \& Pinto-Gouveia, 2010; Pinto-Gouveia, \& Matos, 2011), which sustain that traumatic and central shame memories an and shame predict psychopathology.

In conclusion, our findings support the evolutionary model that suggests there are two distinct types of 'conspecific' anxiety, with different evolutionary histories, functions and psychological processes (Gilbert, 2001). In particular, the present study supports the claim of different psychological processes underlying two forms of social wariness. Paranoia is focused on malevolence and negative intentions of others towards the self, whereas social anxiety is focused on our abilities to be attractive to others and compete 
for social place and avoid rejection. These two anxieties clearly overlap and can coexist, and both are related to shame. However, paranoid anxiety is more linked to how one believes one exists in the minds of others whereas social anxiety seems to be more related to beliefs and feelings about one's own inadequacies and shortcomings. We would hypothesise that people with paranoid anxiety would want to keep away from others whereas those with social anxiety would like to feel included, valued and accepted by others, possibly by having desirable qualities. In addition, traumatic impact of shame memories and the centrality of shame memories seem to be specifically associated with paranoid ideation but not with social anxiety. This points to the importance of malevolent rearing experiences, where the self may have been harmed, abused, neglected or rejected by significant others, which can become traumatic and central AMs to social wariness and to the development of paranoid anxiety.

\section{Clinical implications}

The current study may contribute to a better understanding of paranoia and social anxiety, shedding some light on the way shame and shame experiences are related to these two evolutionary forms of social wariness and anxiety.

Despite the use a non-clinical sample, some therapeutic implications might be drawn from our findings since the same mechanisms and processes involved in shame and shame memories should apply at a clinical or non-clinical level. Therefore, the present study underlines the importance of assessing and working with shame in dealing with paranoid or socially anxious individuals (Gilbert, 2006, 2007b, 2009; Gilbert, \& Irons, 2005; Gilbert, \& Procter, 2006). Moreover, our results highlight the importance of addressing and reconstructing the meaning associated with traumatic and central shame 
memories, particularly in patients experiencing a more malevolent or paranoid form of 'social' anxiety (Gilbert, 2010; Robinson, 1996; Robinson \& Taylor, 1998).

\section{Limitations \& Future research}

One methodological limitation of the present study is its cross-sectional design. In the future, prospective studies should be carried out to enhance the understanding on the causal relation between the variables. Despite the plausibility of the models tested here, there may be other concurrent explanatory models for these relations using other variables or considering other types or directions of association. These concurrent models could be tested in future studies. Since we used a general community sample, the current results cannot be generalised to clinical populations and, for this reason, we are now replicating this study using a clinical sample. The use of the Experience of Shame Scale (Andrews et al., 2002) to assess internal shame might also raise some concerns, since this scale comprises a few items that might be related to external shame (e.g. "Have you worried about what other people think of the sort of person you are?"). Future studies should seek to replicate the present findings using other instruments to measure internal shame, such as the Internalised Shame Scale (Cook, 1996).

Nonetheless, this is the first study to show that current shame and shame memories are distinctly related to paranoid and social anxiety in a general population, empirically supporting the idea that shame memories that function as traumatic central events to personal identity and life story are particularly important for those experiencing paranoia, but not social anxiety. 


\section{Acknowledgments}

This research has been supported by the first author (Marcela Matos) Ph.D. grant number SFRH/BD/36617/2007, sponsored by FCT (Portuguese Foundation for Science and Technology).

\section{References}

Addis, D.R. \& Tippett, L.J. (2008). The contributions of autobiographical memory to the content and continuity of self: a social-cognitive neuroscience approach. In Individual and Collective Self-Continuity, (pp. 71-84). New York: Psychology Press.

Alea, N., \& Bluck, S. (2003). Why are you telling me that? A conceptual model of the social function of autobiographical memory. Memory, 11, 165-178.

Allan, S., Gilbert, P., \& Goss, K. (1994). An exploration of shame measures: II. Psychopathology. Personality and Individual Differences, 17, 719-722.

Andrews, B. (1998). Methodological and Definitional Issues in Shame Research. In P. Gilbert and B. Andrews (Eds.). Shame: Interpersonal Behaviour, Psychopathology and Culture (pp. 39-55). New York: Oxford University Press.

Andrews, B. (2002). Body shame and abuse in childhood. In P. Gilbert and J. Miles (Eds.). Body Shame: Conceptualisation, Research and Treatment (pp. 256-266). London: Brunner.

Andrews, B., \& Hunter, E. (1997). Shame, early abuse, and course of depression in a clinical sample: A preliminary study. Cognition and Emotion, 11, 373-381. 
Andrews, B., Qian. M., \& Valentine, J. (2002). Predicting depressive symptoms with a new measure of shame: The experience of shame scale. The British Journal of Clinical Psychology, 41, 29-33.

Baddeley, A. D. (1986). Working memory. Oxford: Clarendon Press.

Baldwin, M. W. (1992). Relational schema and the processing of social information. Psychological Bulletin, 112, 461-484.

Baumeister, R.F. \& Leary, M.R. (1995). The need to belong: Desire for interpersonal attachments as a fundamental human motivation. Psychological Bulletin, 117, 497529.

Baumeister, R. F., Bratslavsky, E., Finkenauer, C., \& Vohs, K. D. (2001). Bad is stronger than good. Review of General Psychology, 5, 323-370.

Bentall, R.P., Rowse, G., Shryane, N., Kinderman, P., Howard, R., Blackwood, N., Moore, R., \& Corcoran, R. (2009). The cognitive and affective structure of paranoid delusions: a transdiagnostic investigation of patients with schizophrenia spectrum disorders and depression. Archives of General Psychiatry, 66 (3), 236-247

Berntsen, D., \& Rubin, D. C. (2006). Centrality of Event Scale: A measure of integrating a trauma into one's identity and its relation to post-traumatic stress disorder symptoms. Behaviour Research and Therapy, 44, 219-231.

Berntsen, D., \& Rubin, D. C. (2007). When a trauma becomes a key to identity: Enhanced integration of trauma memories predicts posttraumatic stress disorder symptoms. Applied Cognitive Psychology, 21, 417-431.

Bluck, S. (2003). Autobiographical memory: Exploring its functions in everyday life'. Memory, 11(2),113-123.

Bluck S., \& Levine L. J. (1998). Reminiscence as autobiographical memory: A catalyst for reminiscence theory development. Ageing and Society, 18, 185-208. 
Bluck S., Alea N., Habermas T., \& Rubin D.C. (2005). A tale of three functions: The self-reported uses of autobiographical memory. Social Cognition, 23, 91-117.

Boyce, W.T., O'Neill-Wagner, P., Price, C.S., Haines, M., \& Suomi, S.J. (1998). Crowding Stress and Violent Injuries Among Behaviourally Inhibited Rhesus Macaques. Health Psychology, 17 (3), 285-289.

Bowlby, J. (1969/1982). Attachment and loss, Vol. 1: Attachment. London: Hogarth Press.

Bowlby, J. (1973). Attachment and loss, Vol. 2: Separation. London: Hogarth Press.

Bowlby, J. (1980). Attachment and loss, Vol. 3: Loss, sadness and depression. London: Hogarth Press.

Brewin, C., Andrews, B., \& Gotlib, I. (1993). Psychopathology and early experience: a reappraisal of retrospective reports. Psychological Bulletin, 113, 82-98.

Brewin, C., Reynolds, M., \& Tata, P. (1999). Autobiographical memory processes and the course of depression. Journal of Abnormal Psychology, 108, 511-517.

Byrne, B. (2010). Structural Equation Modeling with AMOS: Basic Concepts, Applications, and Programming (2nd ed.) New York: Routledge.

Byrne, R. W. (1995). The thinking ape. Oxford: Oxford University Press.

Chadwick, P.D.J., \& Trower, P. (1997). To defend or not to defend: A comparison of paranoia and depression. Cognitive Psychotherapy: An International Quarterly, 11, $63-71$.

Clark, D.M., \& Wells, A. (1995). A cognitive model of social phobia. In R.G. Heimberg, M. Liebowitz, D. Hope, and F. Scheier (Eds.) Social Phobia: Diagnosis, Assessment, and Treatment (pp 69-93). Guilford: New York. Cohen, G. (1998). The effects of aging on autobiographical memory. In C. Thompson, D. Herrmann, D. 
Bruce, J.D. Read, D. Payne, and M. Toglia (Eds.), Autobiographical Memory: Theoretical and Applied Perspectives (pp 105-123). London: Lawrence Earlbaum.

Cohen, J., Cohen, P., West, S., \& Aiken, L. (2003). Applied multiple regression/correlation analysis for the behavioural sciences (3th ed.). New Jersey: Lawrence Erlbaum Associates.

Combs D.R., Penn D.L., Chadwick , P., Trower, P., Michael, C.O., \& Basso, M.R. (2007) Subtypes of paranoia in a nonclinical sample . Cognitive Neuropsychiatry, 12 (6), $537-553$

Conway, M. A. (2005). Memory and the self. Journal of Memory and Language, 53, $594-628$.

Conway, M. (2003). Commentary Cognitive-affective mechanisms and processes in autobiographical Memory. Memory,11(2), 217-224. DOI: 10.1080/741938205

Conway, M.A. (2003). Cognitive-affective mechanisms and processes in autobiographical memory. Memory, 11, 217-224.

Conway M.A. (2005). Memory and the self. Journal of Memory and Language, 53, 594628.

Conway, M. A., Meares, K., \& Standart, S. (2004). Images \& goals. Memory, 12, 525531.

Conway M.A., \& Pleydell-Pearce C.W. (2000). The construction of autobiographical memories in the self-memory system. Psychological Review, 107, 261-88.

Conway M.A., \& Rubin D.C. (1993). The structure of autobiographical memory. In A.F. Collins, S.E. Gathercole, M.A. Conway, P.E. Morris (Eds.), Theories of memory. (pp. 103-39). Hillsdale, NJ: Erlbaum. 
Cook, D. (1996). Empirical Studies of Shame and Guilt: The Internalized Shame Scale. In D. L. Nathanson (Ed.). Knowing Feeling. Affect, Script and Psychotherapy (pp. 132-165). New York: W. W. Norton \& Company.

Corcoran, R. \& Kaiser, S. (2008). Persecutory Delusions and Theory of Mind: longstanding debates and emerging issues. In D. Freeman, R. P. Bentall \& P. Garety (Eds.), Persecutory Delusions: Assessment, Theory and Treatment (pp. 205-220). Oxford: University Press.

Corcoran, R., Mercer, G., \& Frith, C. (2005). Schizophrenia, symptomatology and social inference: investigating theory of mind in people with schizophrenia. Schizophrenia Research, 24, 397-405.

de Mendoza, A. H., Fernandez-Dols, J. M., Parrott, W. G., \& Carrera, P. (2010). Emotion terms, category structure, and the problem of translation: The case of shame and verguenza. Cognition and Emotion, 24, 661-680.

Dickerson, S. S., \& Kemeny, M. E. (2004). Acute stressors and cortisol response: A theoretical integration and synthesis of laboratory research. Psychological Bulletin, $130,335-391$.

Dugnan, D., Trower, P. \& Gilbert, P. (2002) Measuring vulnerability to threats to self construction: The self and other scale. Psychology and Psychotherapy: Theory Research and Practice, 75, 279-294.

Ehlers, A., \& Clark, D.M. (2000). A cognitive model of posttraumatic stress disorder. Behaviour Research and Therapy, 38, 319-345.

Etcoff, N. (1999). Survival of the Prettiest: The Science of Beauty. New York: Doubleday Ellett, L., Lopes, B., \& Chadwick, P. (2003). Paranoia in a Normal College Population. Journal of Nervous and Mental Disease, 191 (7), 425-230. 
Fenigstein, A., \& Vanable, P. A. (1992). Paranoia and self-consciousness. Journal of Personality and Social Psychology, 62, 129-138.

Freeman, D. (2007). Suspicious Minds: the psychology of persecutory delusions. Clinical Psychology Review, 27, 425-457.

Freeman, D., Bentall, R. P., \& Garety, P., (Eds.) (2008). Persecutory Delusions: Assessment, Theory and Treatment. Oxford: University Press.

Freeman, D., Garety, P.A., Kuipers, E., Fowler, D., \& Bebbington, P.E. (2002) A cognitive model for persecutory delusions. British Journal of Clinical Psychology, $41(4), 331-47$.

Freeman, D., \& Garety, P. A. (2004). Paranoia: The Psychology of Persecutory Delusions. Hove: Psychology Press.

Freeman, D., Garety, P. A., Bebbington, P.E., Smith, B., Rollinson, R., Fowler, D., Kuipers, E., Ray, K. \& Dunn, G. (2005). Psychological investigation of the structure of paranoia in a non-clinical population. British Journal of Psychiatry, $186,427-435$.

Frith, C. (1992). The cognitive neuropsychology of schizophrenia. Hillsdale, NJ: Erlbaum.

Frith, C. (1994). Theory of mind in schizophrenia. In A. David \& J. Cutting (Eds.), The neuropsychology of schizophrenia (pp. 147-162). Hillsdale, NJ: Erlbaum.

Gilbert, P. (1997). The evolution of social attractiveness and its role in shame, humiliation, guilt and therapy. British Journal of Medical Psychology, 70, 113-147.

Gilbert, P. (1998a). The evolved basis and adaptive functions of cognitive distortions. British Journal of Medical Psychology, 71, 447-463. 
Gilbert, P. (1998b). What Is Shame? Some Core Issues and Controversies. In P. Gilbert and B. Andrews (Eds.). Shame: Interpersonal Behaviour, Psychopathology and Culture (pp. 3-36). New York: Oxford University Press.

Gilbert, P. (2000). The Relationship of Shame, Social Anxiety and Depression: The Role of the Evaluation of Social Rank. Clinical Psychology and Psychotherapy, 1, 174189.

Gilbert, P. (2001). Evolution and social anxiety. The role of attraction, social competition and social hierarchies. The Psychiatric Clinics of North America, 24 (4), 723-751.

Gilbert, P. (2002a). Evolutionary approaches to psychopathology and cognitive therapy. Journal of Cognitive Psychotherapy, 16, 263-294.

Gilbert, P. (2002b). Body Shame: A Biopsychosocial Conceptualisation and Overview, with Treatment Implications. In P. Gilbert and J. Miles (Eds.). Body Shame: Conceptualisation, Research and Treatment (pp. 3-54). London: Brunner.

Gilbert, P. (2003). Evolution, Social Roles and the Differences in Shame and Guilt. Social Research, 70, 1205-1230.

Gilbert, P. (2006). A biopsychosocial and evolutionary approach to formulation with a special focus on shame. In N. Tarrier (Ed.). Case Formulation in Cognitive Behaviour Therapy: The Treatment of Challenging and Complex Cases (pp. 81112). Hove: Routledge.

Gilbert, P. (2007a). The evolution of shame as a marker for relationship security. In J.L. Tracy, R.W. Robins \& J.P. Tangney (Eds.). The Self-Conscious Emotions: Theory and Research. (pp. 283-309). New York: Guilford.

Gilbert, P. (2007b). Evolved minds and compassion in the therapeutic relationship. In N. P. Gilbert and R. Leahy (Eds.). The Therapeutic Relationship in the Cognitive Behavioural Psychotherapies (pp. 106-142). Hove: Routledge. 
Gilbert, P. (2009). The Compassionate Mind: A New Approach to Life's Challenges London: Constable \& Robinson.

Gilbert, P. (2010). Compassion Focused Therapy: Distinctive Features. London: Routledge.

Gilbert, P., Price, J. S., \& Allan, S. (1995). Social comparison, social attractiveness and evolution: How might they be related? New Ideas in Psychology, 13, 149-165.

Gilbert, P., Allan, S., \& Goss, K. (1996). Parental Representations, Shame, Interpersonal Problems, and Vulnerability to Psychopathology. Clinical Psychology and Psychotherapy, 3, 23-34.

Gilbert, P. \& McGuire M. (1998). Shame, Social Roles and Status: The Psychobiological Continuum from Monkey to Human. In P. Gilbert and B. Andrews (Eds.). Shame: Interpersonal Behaviour, Psychopathology and Culture (pp. 99-125). New York: Oxford University Press.

Gilbert, P., \& Miles, J.N.V. (2000). Sensitivity to put-down: Its relationship to perceptions of shame, social anxiety, depression, anger and self-other blame. Personality and Individual Differences, 29, 757-774.

Gilbert, P., \& Trower, P. (2001). Evolutionary psychology and social anxiety. In Crozier W. R. and Alden L. E. (Eds.): The Self, Shyness and Social Anxiety: A Handbook of Concepts, Research and Interventions. Chichester: John Wiley \& Sons.

Gilbert, P. \& Trower, P. (1990). Social Anxiety: Evolution and manifestation. In, R. Cozier (ed.). Shyness and Embarrassment: Perspectives from Social Psychology. (pp. 144-177) Cambridge: Cambridge University Press.

Gilbert, P., Boxall, M., Cheung, M., \& Irons, C. (2005). The relation of paranoid ideation and social anxiety in a mixed clinical population. Clinical Psychology and Psychotherapy, 12, 124-133. 
Gilbert, P. \& Irons, C., (2005). Focused therapies and compassionate mind training for shame and self attacking. In P. Gilbert (Ed.). Compassion: Conceptualisations, Research and Use in Psychotherapy (pp. 263-325). London: Routledge.

Gilbert, P., \& Procter, S. (2006). Compassion mind training for people with high shame and self criticism: Overview and pilot study. Clinical Psychology and Psychology, $13,353-379$.

Gilbert, P., Broomhead, C., Irons, C, McEwan, K, Bellew, R., Mills, A \& Gale, C. (2007). Striving to avoid inferiority: Scale development and its relationship to depression, anxiety and stress. British Journal of Social Psychology, 46, 633-648.

Goodall, J. (1990). Through a window: Thirty Years with the Chimpanzees of Gnome. Harmondsworth: Penguin.

Goss, K., Gilbert, P., \& Allan, S. (1994). An Exploration of Shame Measures I. The “Other as Shamer Scale”. Personality and Individual Differences, 17, 713-717.

Gracie, A., Freeman, D., Green, S., Garety P. A., Kuipers, E., Hardy, A., Ray, K., Dunn, G., Bebbington, P., \& Fowler, D. (2007) The association between traumatic experience, paranoia and hallucinations: a test of the predictions of psychological models. Acta Psychiatrica Scandinavica, 116 (4), 280-289.

Green, M. J., \& Phillips, M. L. (2004). Social threat perception and the evolution of paranoia. Neurosciences and Biobehavioral Reviews, 28, 333-342.

Greenberg, D., Rice, H., Cooper, J., Cabeza, R., Rubin, D., \& LaBar, K. (2005). Coactivation of the amygdala, hippocampus and inferior frontal gyrus during autobiographical memory retrieval. Neuropsychologia, 43, 659-674.

Habermas \& Bluck, (2000). Getting a life: The emergence of life story in adolescence. Psychological Bulletin, 126, 748-769. 
Hackman, A., Surawy, C., \& \& Clark, D.M. (1998). Seeing yourself through others' eyes: A study of spontaneous occurring images in social phobia. Behavioural and Cognitive Psychotherapy, 26, 3-12.

Higley, J.D., Mehlman, P.T., Higley, S., Fremald, B., Vickers, J., Lindell, S.G., Taub, D.M., Suomi, S.J. \& Linnoila, M. (1996). Excessive mortality in young free-ranging male nonhuman primates with low cerebrospinal fluid 5-hydroxyindoleacetic acid concentrations. Archives of General Psychiatry, 53, 537-543.

Holland A. C. \& Kesinger, E.A. (2010). Emotion and autobiographical memory. Physics of Life Reviews, 7 ,88-131.

Honess, P.E., \& Marin, C.M. (2006). Behavioural and physiological aspects of stress and aggression in nonhuman primates. Neuroscience and Biobehavioural Reviews, 30, $390-412$.

Judd, C. M. (2000). Everyday data analysis in social psychology: Comparisons of Linear Models (Chapter 14, pp. 370-392). In H. T. Reis \& C. M. Judd (Eds.), Handbook of research methods in social and personality psychology. Cambridge, UK: Cambridge University Press.

Keltner, D., \& Harker, L. (1998). The forms and functions of the nonverbal signal of shame. In P. Gilbert \& B. Andrews (Eds.). Shame: Interpersonal Behaviour, Psychopathology and Culture (pp. 78-98). New York: Oxford University Press.

Kihlstrom, J. F. (2009). So That We Might Have Roses in December': The Functions of Autobiographical Memory. Applied Cognitive Psychology, 23, 1179-1192.

Kline, R. B. (2005). Principles and practice of structural equation modeling (2nd ed.). New York: Guilford Press.

Leary, M.R. (1995). Self-Presentation: Impression Management and Interpersonal Behaviour. Madison, WI: Brown \& Bencmark. 
Levine, L. J., \& Pizarro, D. A. (2004). Emotion and memory research: A grumpy overview. Social Cognition, 22, 530-554.

Lewis, M. (1992). Shame: The Exposed Self: New York: The Free Press.

Lopes, B., \& Pinto-Gouveia, J. (2005). Portuguese version of the 'General Paranoia Scale'. Unpublished manuscript.

Lysaker, P.H., Salvatore, G., Grant, M.L., Procacci, M., Olesek, K.L., Buck, K.D., Nicolò, G., \& Dimaggio, G. (2010). Deficits in theory of mind and social anxiety as independent paths to paranoid features in schizophrenia. Schizophrenia Research, $124,81-85$.

Martin, J.A., \& Penn, D.L. (2001) Brief report: Social cognition and subclinical paranoid ideation. British Journal of Clinical Psychology, 40, 261-265.

Matos, M., \& Pinto-Gouveia, J. (2010). Shame as a Traumatic Memory. Clinical Psychology and Psychotherapy, 17, 299-312. DOI: 10.1002/cpp.659

Matos, M., Pinto-Gouveia, J., \& Duarte, C. (2011a). Other as Shamer: Versão portuguesa e propriedades psicométricas de uma medida de vergonha externa. Submitted manuscript.

Matos, M., Pinto-Gouveia, J., \& Duarte, C. (2011b). Study of the psychometric properties of the Portuguese version of the Experience of Shame Scale. Manuscript in preparation

Matos, M., Pinto-Gouveia, J., \& Gomes, P. (2010). A centralidade das experiências de vergonha: Estudo de validação da versão portuguesa da Escala da Centralidade do Acontecimento (CES). Psicologia,XXIV (1), 73-95.

Matos, M., Pinto-Gouveia, J., \& Martins, S. (2010). Propriedades psicométricas da versão portuguesa da Escala do Impacto do Acontecimento-Revista (IES-R). Psychologica, 52 (In press) 
MacBeth, A., Schwannauer, M., \& Gumley, A. (2008). The association between attachment style, social mentalities, and paranoid ideation: An analogue study. Psychology and Psychotherapy: Theory, Research and Practice, 81, 79-93. doi: $10.1348 / 147608307 X 246156$.

MacDonald, G. \& Leary, M.R. (2005). Why does social exclusion hurt? The relationship between social and physical pain. Psychological Bulletin, 131, 202-223.

McAdams, D. P. (1996). Personality, modernity, and the storied self: A contemporary framework for studying persons. Psychological Inquiry, 7, 295-3210.

McLean, K. C. (2005). Late adolescent identity development: Narrative meaning-making and memory telling. Developmental Psychology, 41, 683-691.

McLean, K. C., \& Thorne, A. (2003). Adolescents' self-defining memories about relationships. Developmental Psychology, 39, 635-645.

McNeil, D.W., Ries, B.J., \& Turk, C.L. (1995). Behavioural assessment: Self- and otherreport, physiology and overt behaviour. In R.G. Heimberg, M.R. Liebowitz, D.A. Hope and F.R. Schneier, (Eds.). Social Phobia: Diagnosis, assessment and treatment (pp. 202-231). Guilford Press: New York.

Mills, A., Gilbert, P., Bellew, R., McEwan, K., \& Gale, C. (2007). Paranoid beliefs and self-criticism in students. Clnical Psychology and Psychotherapy, 14, 358-364.

Ogilive, D.M. (1987). The undesired self: A neglected variable in personality research. Journal of Personality and Social Psychology, 52, 379-388.

Ogilvie, D. M., \& Rose, K. M. (1995). Self-with-other representations and taxonomy of motives: Two approaches to studying persons. 63, 643-679.

Pasupathi, M. (2003). Emotion regulation during social remembering: Differences between emotions elicited during an event and emotions elicited when talking about it. Memory, 11(2),151-163. DOI: 10.1080/741938212 
Patel, T., Brewin C. R., Wheatley, J., Wells, A., Fisher, P., \& Myers, S. (2007). Intrusive images and memories in major depression. Behaviour Research and Therapy, 45, 2573-2580.

Pickering, L., Simpson, J., \& Bentall, R.P. (2008). Insecure attachment predicts proneness to paranoia but not hallucinations. Personality and Individual Differences. 44 (5), 1212-1224.

Pillemer, D. B. (1998). Momentous Events, Vivid Memories. Cambridge, MA: Harvard University Press.

Pillemer, D. B. (2003). Directive functions of autobiographical memory: The guiding power of the specific episode. Memory,11(2),193-202. DOI: 10.1080/741938208

Pinto-Gouveia, J. (1999). Ansiedade Social: da timidez à fobia social. Coimbra: Quarteto.

Pinto-Gouveia, J., Fonseca, L., Robalo, M., Allen, A., Matos, A.P., \& Gil, E. (1986). Ansiedade social: utilização dos questionários de auto-resposta $S A D, F N E$ e $S I S S T$ numa população portuguesa. Psiquiatria Clínica, 7, 43-48.

Pinto-Gouveia, J. A., Cunha, M. I., \& Salvador, M. C. (2003). Assessment of social phobia by self-report questionnaires: The Social Interaction and Performance Anxiety and Avoidance Scale and the Safety Behaviours Scale. Behavioural and Cognitive Psychotherapy, 31, 291-311.

Pinto-Gouveia, J. \& Matos, M. (2011). Can shame memories become a key to identity? The centrality of shame memories predicts psychopathology. Applied Cognitive Psychology, 25, 281-290. DOI: 10.1002/acp1689.

Porges, S.W. (2007). The Polyvagal Perspective. Biological Psychology, 74, 116-143.

Reynolds, M. \& Brewin, C. R. (1999) Intrusive memories in depression and posttraumatic stress disorder. Behaviour Research \& Therapy, 37, 201-215. 
Robinson, J. A. (1996). Perspective, meaning and remembering. In D. C. Rubin, (Ed.) Remembering our past: Studies in autobiographical memory (pp. 199-217). Mahwah, NJ: Lawrence Erlbaum Associates.

Robinson, J. A., \& Swanson, K. L. (1990). Autobiographical memory: The next phase. Applied Cognitive Psychology, 4, 321-335.

Robinson, J. A., \& Taylor, L. R. (1998). Autobiographical memory and self-narratives: A tale of two stories. In C. P. Thompson, D. J. Herrmann, D. Bruce, J. D. Read, D. G. Payne, \& M. P. Toglia (Eds.) Autobiographical memory: Theoretical and applied perspectives (pp. 125-143). Mahwah, NJ: Lawrence Erlbaum Associates.

Rubin, D. (2005). Basic-systems approach to autobiographical memory. Current Directions in Psychological Science, 14, 79-83.

Rubin, D., Schrauf, R. \& Greenberg, D. (2003). Belief and recollection of autobiographical memories. Memory and Cognition, 31, 887-901.

Salvatore, G., Lysaker, P. H., Popolo, R., Procacci, M., Carcione, A. and Dimaggio, G. (2011). Vulnerable Self, Poor Understanding of Others' Minds, Threat Anticipation and Cognitive Biases as Triggers for Delusional Experience in Schizophrenia: A Theoretical Model. Clinical Psychology \& Psychotherapy. doi: 10.1002/cpp.746

Schlenker, B.R., \& Leary, M.R. (1982). Social anxiety and self-presentation: A conceptualization and model. Psychological Bulletin, 92, 641-669.

Singer, J. A., \& Salovey, A. P. (1993). The remembered self. New York: The Free Press.

Tabachnick, B., \& Fidell, L. (2007). Using Multivariate Statistics. New York: Pearson Education Inc.

Tangney, J. (1996). Conceptual and methodological issues in the assessment of shame and guilt. Behaviour Research and Therapy, 34, 741-754.

Tangney, J.P. \& Dearing, R.L. (2002). Shame and Guilt. New York: Guilford Press. 
Tangney, J.P. \& Fischer, K.W. (Eds.). (1995). Self-Conscious Emotions: The Psychology of Shame, Guilt, Embarrassment and Pride. New York: Guilford.

Thorne, A. (1995). Developmental truths in memories of childhood and adolescence. Journal of Personality, 63, 138-163.

Thorne, A. (2000). Personal memory telling and personality development. Personality \& Social Psychology Review, 4, 45-56.

Tomkins, S. S. (1979). Script theory: Differential magnification of affects. In H. E. Howe, Jr. \& R. A. Dienstbier (Eds.), Nebraska symposium on motivation 1978, (Vol. 26, pp. 201-236). Lincoln: University of Nebraska Press.

Tracy, J. L. \& Robins, R. W. (2004). Putting the self into self-conscious emotions: a theoretical model. Psychological Inquiry, 15, 103-125.

Tracy, J. L., \& Robins, R. W. (2007). The self in self-conscious emotions: A cognitive appraisal approach. In J. L. Tracy, R. W. Robins, \& J. P. Tangney (Eds), The self conscious emotions: Theory and research (pp. 3-20). New York: Guilford.

Trower, P., \& Chadwick, P. D. J. (1995). Pathways to defence of the self: A theory of two types of paranoia. Clinical Psychology: Science and Practice, 2, 263-278.

Trower, P., Sherling, G., Beech, J., Horrop, C., \& Gilbert, P. (1998). The socially anxious perspective in face to face interaction: An experimental comparison. Clinical Psychology and Psychotherapy: An International Journal of Theory and Practice, $5,155-166$.

Watson, D., \& Friend, R. (1969). Measurement of social evaluative anxiety. Journal of Consulting and Clinical Psychology, 33, 448-457.

Weiss, D. S., \& Marmar, C. R. (1997). The Impact of Event Scale - Revised. In J. P. Wilson, \& T. M. Keane (Eds.). Assessing Psychological trauma and PTSD (pp. 399-411). New York: Guilford Press. 
Wilson, A. E., \& Ross, M. (2003). The identity function of autobiographical memory. Time is on our side. Memory, 11, 137-150.

Woike, B. A. (2008). A functional framework for the influence of implicit and explicit motives on autobiographical memory. Personality and Social Psychology Review, $12,99-117$. 
Table 1: Means $(M)$ and standard deviations $(S D)(N=328)$

\begin{tabular}{lcc}
\hline & \multicolumn{2}{c}{ Total } \\
Variables & $(N=328)$ \\
\cline { 2 - 3 } & $M$ & $S D$ \\
\hline Shame & & \\
Other As Shamer (OAS) & 19.60 & 9.45 \\
Experience of Shame Scale (ESS) & 47.52 & 13.14 \\
Centrality of shame memory & & \\
Centrality of Event Scale (CES) & & \\
Traumatic impact of shame memory & & \\
Impact of Event Scale _Revised (IES-R) & 3.88 & 2.77 \\
Paranoia & & \\
General Paranoia Scale (GPS) & & \\
Social anxiety & & \\
SIPAAS & & \\
\hline
\end{tabular}


Table 2: Intercorrelations (2-tailed Pearson $r$ ) between external shame, internal shame, centrality of shame memories, traumatic impact of shame memory, paranoia and social anxiety $(N=328)$

\begin{tabular}{cccccc}
\hline & OAS & ESS & CES & IES-R & GPS \\
\hline ESS & $.51 * *$ & & & & \\
CES & $.34 * *$ & $.32 * *$ & & & \\
IES-R & $.47 * *$ & $.47 * *$ & $.63 * *$ & & \\
GPS & $.61 * *$ & $.46^{* *}$ & $.45^{* *}$ & $.53 * *$ & \\
SIPAAS & $.43^{* *}$ & $.57 * *$ & $.19 * *$ & $.38^{* *}$ & $.40^{* *}$ \\
\hline
\end{tabular}

Note. ${ }^{*} p<.050, * * p<.010$.

Key: OAS, External shame; ESS, Internal shame; CES, Centrality of shame memory; IES-R, Traumatic impact of shame memory; GPS, General paranoia scale; SIPAAS, Social interaction and performance anxiety and avoidance scale. 
Table 3. Paths in Model A and in Model B with their Standardised Regression Weights including the Overall Fit Indices for Models

Standardised Regression

Weights

\begin{tabular}{|c|c|c|}
\hline \multicolumn{3}{|l|}{ Paths in Model A } \\
\hline IES-R $\rightarrow$ GPS & & $.274 * * *$ \\
\hline $\mathrm{OAS} \rightarrow \mathrm{GPS}$ & & $.419 * * *$ \\
\hline $\mathrm{ESS} \rightarrow \mathrm{GPS}$ & & $.116^{*}$ \\
\hline IES-R $\rightarrow$ SIPAAS & & .097 \\
\hline OAS $\rightarrow$ SIPAAS & & $.149 * *$ \\
\hline $\mathrm{ESS} \rightarrow \mathrm{SIPAAS}$ & & $.449 * * *$ \\
\hline \multicolumn{3}{|l|}{ Paths in Model B } \\
\hline $\mathrm{CES} \rightarrow \mathrm{GPS}$ & & $.256 * * *$ \\
\hline $\mathrm{OAS} \rightarrow \mathrm{GPS}$ & & $.443 * * *$ \\
\hline $\mathrm{ESS} \rightarrow \mathrm{GPS}$ & & $.149 * *$ \\
\hline $\mathrm{CES} \rightarrow$ SIPAAS & & -.028 \\
\hline OAS $\rightarrow$ SIPAAS & & $.185 * * *$ \\
\hline $\mathrm{ESS} \rightarrow$ SIPAAS & & $.485 * * *$ \\
\hline Goodness-of-fit indices & Model A & Model B \\
\hline Chi-square $\left(\chi^{2}\right)$ & $2.45(d f=1 ; p<.12)$ & $5.38(d f=1 ; p<.02)$ \\
\hline GFI (goodness-of-fit index) & .997 & .994 \\
\hline AGFI (adjusted goodness-of-fit index) & .955 & .903 \\
\hline CFI (comparative fit index) & .997 & .991 \\
\hline TLI (Tucker-Lewis index) & .973 & .908 \\
\hline RMSEA (root mean-square error of approximation) & .066 & .116 \\
\hline SRMR (standardised root mean square residual) & .013 & .019 \\
\hline
\end{tabular}

Note. ${ }^{*} p<.050, * * p<.010, * * * p<.001$

Key: OAS, External shame; ESS, Internal shame; IES-R, Traumatic impact of shame memory; CES, Centrality of shame memory; GPS, General paranoia scale; SIPAAS, Social interaction and performance anxiety and avoidance scale. 


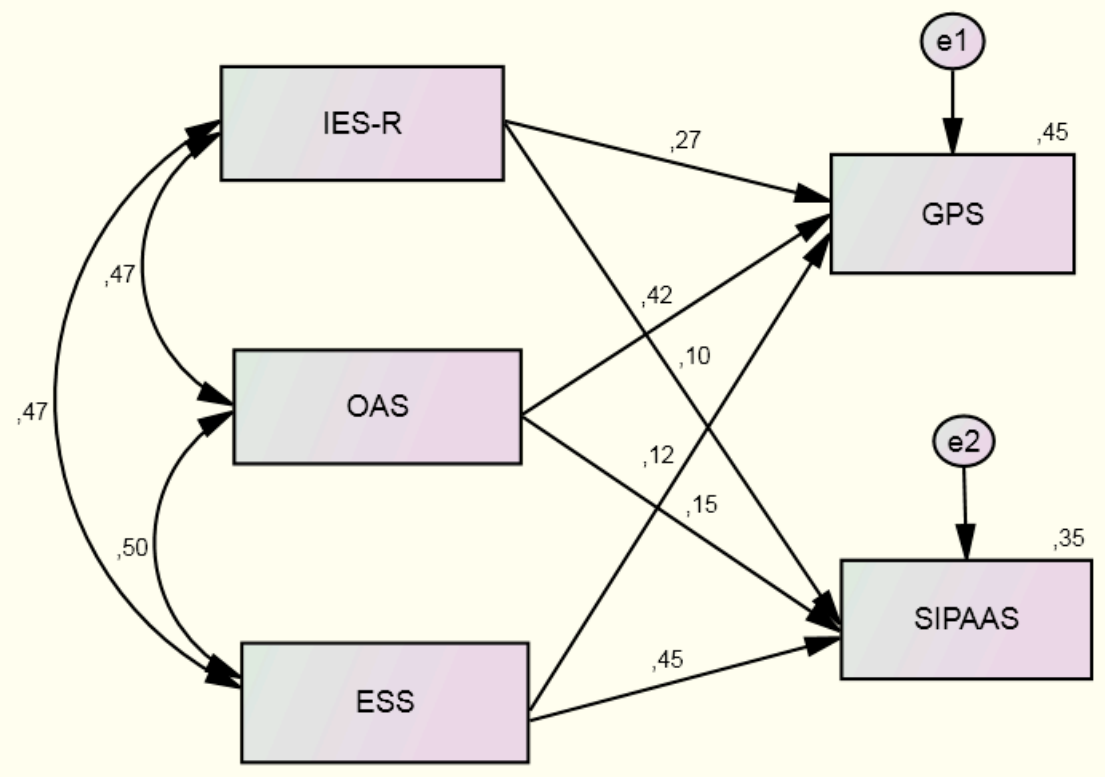

Fig. 1. Results of path analysis (Model A) showing the relationships among traumatic impact of shame memory (IES-R), external shame (OAS), internal shame (ESS), and paranoia (GPS) and social anxiety (SIPAAS) variables with standardised estimates $(N=328)$ 


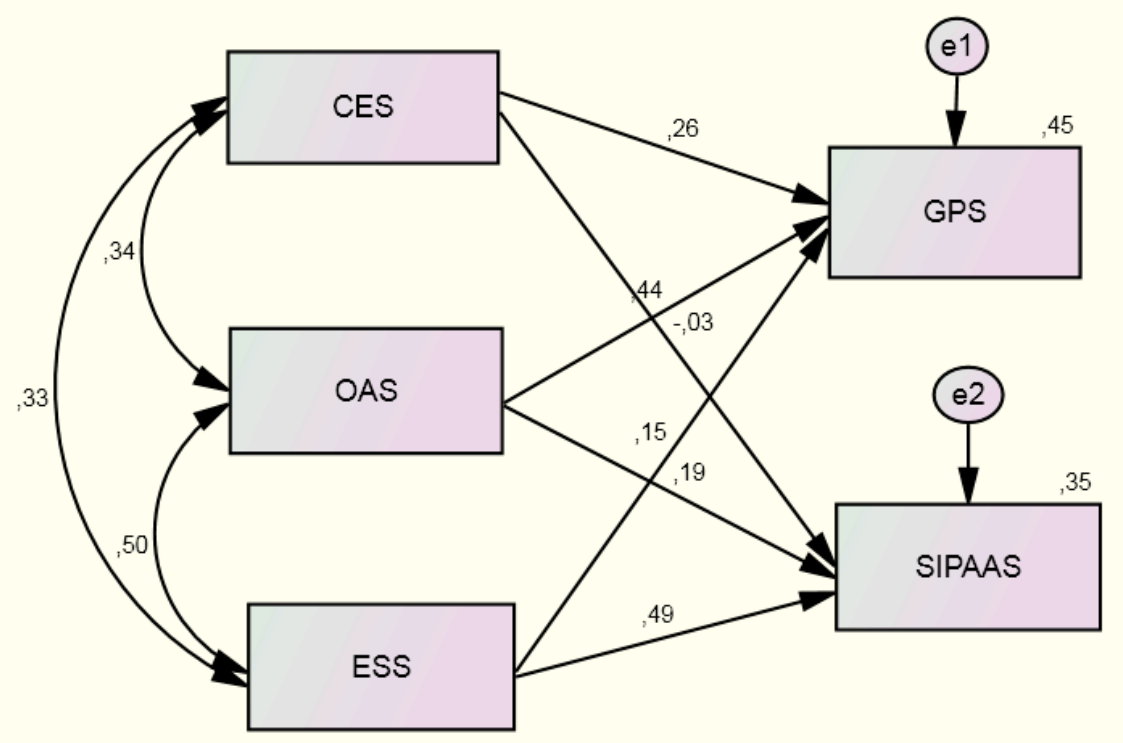

Fig. 2. Results of path analysis (Model B) showing the relationships among centrality of shame memory (CES), external shame (OAS), internal shame (ESS), and paranoia (GPS) and social anxiety (SIPAAS) variables, with standardised estimates $(N=328)$ 